\title{
APROVEITAMENTO DE RESÍDUOS DE ÓLEOS VEGETAIS NA FORMULAÇÃO DE SABÕES EM BARRA ENRIQUECIDOS COM EXTRATOS DE PLANTAS MEDICINAIS
}

\author{
N. R. OLIVEIRA ${ }^{1}$, G. N. MEROLA ${ }^{1}$, M. H. OKURA ${ }^{2}$, A. C. G. MALPASS ${ }^{1}$ e P. P. SILVA ${ }^{1}$ \\ ${ }^{1}$ Universidade Federal do Triângulo Mineiro, Faculdade de Engenharia Química \\ ${ }^{2}$ Universidade Federal do Triângulo Mineiro, Faculdade de Engenharia de Alimentos \\ E-mail para contato: priscaps@yahoo.com
}

\begin{abstract}
RESUMO - Devido ao crescente aumento do consumo de alimentos fritos, surge a preocupação quanto ao descarte do óleo residual do processo de fritura. Se descartado de forma inapropriada na rede esgoto ou em corpos d'água, este pode causar prejuízos irreversíveis ao meio ambiente, além de danos às estações de tratamento. A produção de sabão a partir de óleo residual é uma alternativa sustentável e barata, que minimiza os danos causados por este resíduo. Partindo deste pressuposto, este trabalho propõe o aproveitamento do óleo residual de fritura no desenvolvimento de sabões em barra com adição de extratos de calêndula, barbatimão e própolis que são uma alternativa para a substituição de antissépticos e desinfetantes sintéticos convencionais. Os resultados obtidos mostraram que os sabões acrescidos dos extratos das três plantas possuem ação antibacteriana para Staphylococcus aureus.
\end{abstract}

\section{INTRODUÇÃO}

A atual preocupação com o meio ambiente e sustentabilidade tem alcançado diversos setores, como órgãos governamentais e indústrias. Constantes revisões estão sendo feitas em resoluções relacionadas a resíduos, e assuntos como Gestão Ambiental e ISO 14.000 estão sempre em destaque. Se tratados com tecnologia adequada, os resíduos podem ser convertidos em produtos comerciais ou utilizados como matéria-prima para outros processos. A geração de resíduos sólidos é um fato comum às indústrias alimentícias, principalmente aquelas que produzem como resíduo o óleo de fritura, como por exemplo, as indústrias de produtos prontos para o consumo. No Brasil são descartados cerca de 9.000.000.000 L de resíduo de óleo vegetal por ano, e apenas 2,5\% é reciclado (Souza, (2013)).

A fim de otimizar os processos de fritura e garantir produtos de melhor qualidade, é importante entender as mudanças funcionais, sensoriais e nutricionais que ocorrem nos óleos vegetais durante o aquecimento. Existem vários parâmetros que estabelecem o ponto de descarte de um óleo, porém, devido à complexidade do processo que apresenta variações em relação ao tipo de óleo, alimento, equipamento e condições de operação, não há um método analítico capaz de detectar todas as situações que envolvem a deterioração dos óleos (Corsini; Jorge (2006)). O óleo residual de fritura pode ser reciclado e utilizado para a produção de sabão caseiro. Os sabões sais de ácidos carboxílicos de cadeia longa, são obtidos pela 
hidrólise básica em temperaturas elevadas, sendo esta reação chamada de saponificação. A reação ocorre na presença de bases fortes, sendo utilizada geralmente a soda cáustica (Alberci; Pontes (2004)).

O último século foi marcado pela busca de compostos com propriedades terapêuticas, tendo sido descobertas diversas substâncias com atividade antimicrobiana (Voss - Rech et. al, (2011)). Aliado a isso, tem-se a preocupação cada vez maior com a redução de infecções, que faz com que a população adquira produtos com propriedades microbicidas, com destaque para as substâncias encontradas em plantas e que naturalmente possuem essas propriedades. Tais substâncias possuem grande potencial para ser utilizadas em produtos de limpeza, como o sabão (Souza (2013)). Assim, o objetivo principal deste trabalho foi verificar a viabilidade de aproveitamento do óleo residual no desenvolvimento de sabões em barra com adição de extratos de calêndula, barbatimão e própolis a fim de se obter um sabão de se obter um sabão de boa qualidade com atividades terapêuticas. Para isso, foi realizada a caracterização do óleo residual, o levantamento de dados cinéticos da reação de saponificação e, por último, a análise microbiológica do produto final a fim de avaliar sua eficácia de assepsia.

\section{MATERIAIS E MÉTODOS}

\subsection{Caracterização do Óleo Residual}

O óleo de soja residual foi proveniente de lanchonetes da cidade de Araxá-MG.

\subsubsection{Umidade}

A técnica foi realizada no Analisador de Umidade por infravermelho da marca GEHAKA, modelo IV2500. As análises foram realizadas à $105^{\circ} \mathrm{C}$ durante 30 min. Para todos os testes foram utilizadas $3 \mathrm{~g}$ de amostra (óleo residual).

\subsubsection{Densidade}

A densidade foi obtida pelo método da picnometria e calculada pela Equação 1 .

$$
\rho_{\mathrm{o}}=\frac{\mathrm{m}_{\mathrm{o}}}{V_{\mathrm{p}}}
$$

Equação 1

Sendo: $\rho_{\mathrm{o}}$ (densidade do óleo); $\mathrm{m}_{\mathrm{o}}$ (massa do óleo); $\mathrm{V}_{\mathrm{p}}$ (volume do picnômetro)

\subsection{3. Índice de acidez}

Para a determinação do índice de acidez utilizou-se a metodologia proposta pelo Instituto Adolfo Lutz (2008).

\subsection{4. Índice de peróxidos}

Para a determinação do índice de peróxidos utilizou-se o método Cd3d-63 da American Oil Chemists' Society (AOCS, 2009). 


\subsection{Extratos das Plantas Medicinais}

Aproximadamente $5 \mathrm{~g}$ de $C$. officinalis (adquirida na forma desidratada) e $60 \mathrm{~mL}$ de álcool etílico (P.A) foram utilizados para obter-se o extrato bruto. A planta foi extraída por 3 dias e em seguida o extrato foi filtrado e concentrado em evaporador rotativo. Cerca de $10 \mathrm{~g}$ de $S$. adstringens (adquirida na forma seca) e $60 \mathrm{~mL}$ de álcool etílico (P.A) foram utilizados para obter-se o extrato bruto. A planta foi extraída por 3 dias e em seguida o extrato foi filtrado e concentrado em evaporador rotativo. $\mathrm{O}$ extrato aquoso de própolis foi utilizado sem nenhuma interferência em sua composição.

\subsection{Produção de sabões em barra enriquecidos}

Misturou-se $100 \mathrm{ml}$ de óleo residual anteriormente filtrado com algodão como meio filtrante, e $50 \mathrm{ml}$ de álcool etílico (95\%). Essa mistura foi homogeneizada por 30 minutos a fim de clarificar o óleo. Uma solução de hidróxido de sódio foi preparada utilizando-se $33 \mathrm{ml}$ de água purificada por osmose reversa, e 14,94 g de hidróxido de sódio em micropérolas (99\%). Esta solução foi adicionada rapidamente ao béquer após a clarificação. Após a estabilização da temperatura, indicando o fim da reação, acrescentou-se solução de ácido clorídrico $(50 \%)$ para a neutralização, até se obter um valor de $\mathrm{pH}$ próximo a 8 . A Figura 1 representa o fluxograma dos sabões enriquecidos.

Figura 1: Fluxograma da produção de sabões em barra

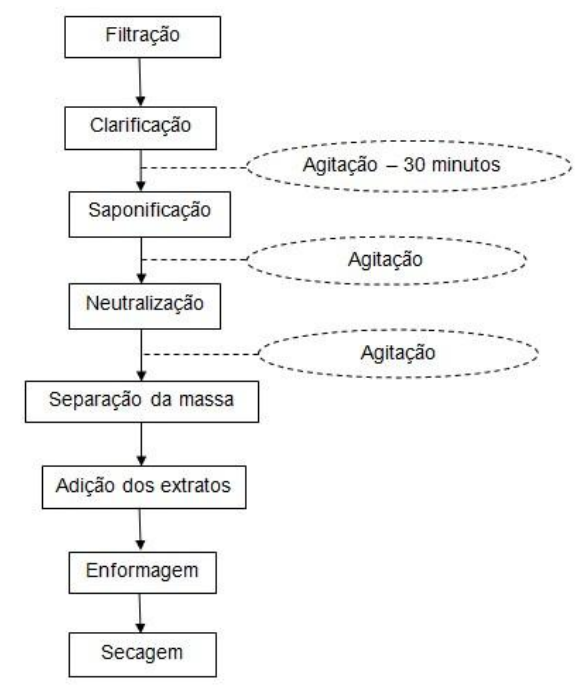

Após a neutralização, a massa resultante foi dividida em três partes, com $50 \mathrm{ml}$ cada, sendo que em cada uma destas partes adicionou-se 2,5 $\mathrm{ml}$ de um tipo de extrato. Logo após, os sabões foram colocados em formas para secagem.

\subsection{Bioensaio de atividade antibacteriana}

Para os bioensaios de difusão em disco, as culturas das bactérias Staphylococcus aureus (S. aureus) e Escherichia coli (E. coli) foram diluídas para uma concentração final de $10^{6}$ células/mL, e $500 \mu \mathrm{L}$ destas soluções foram espalhadas separadamente sobre placas de Petri, 
contendo Ágar Muller Hinton. Foram preparadas soluções aquosas dos três sabões preparados e discos de papel foram embebidos nessas soluções e depositados sobre o Ágar. Além disso, foram feitos três poços em cada uma das placas para o depósito das amostras de sabão, no lugar dos discos. As placas permaneceram à temperatura de $4^{\circ} \mathrm{C}$ por duas horas, e em seguida foram encubadas em estufa BOD a $37^{\circ} \mathrm{C}$ por 24 horas. Após esse tempo, os halos de inibição foram medidos.

\subsection{Levantamento cinético da reação de saponificação}

Para o estudo da cinética da reação de saponificação, os valores de temperatura e $\mathrm{pH}$ foram aferidos inicialmente a cada 10 segundos, com o intervalo crescente à medida que as variações ficavam menores. O programa Excel (2007) foi utilizado para obter os modelos de regressão baseando-se no Método da Integral. O critério para avaliação do ajuste dos modelos foi o coeficiente de regressão linear $\left(\mathrm{R}^{2}\right)$. Um aparato experimental foi montado acoplando-se um multímetro (Politerm, modelo A6), para medição da temperatura, e um pHmetro (Hanna, modelo A2), para medição do $\mathrm{pH}$, a um béquer de $250 \mathrm{ml}$, colocado em um agitador mecânico da marca Tecnal (modelo TE-0851). Após a etapa de clarificação, durante o preparo do sabão, adiciona-se a solução de hidróxido de sódio e inicia-se a cronometragem do tempo, as medições de temperatura e pH. Como a variação de $\mathrm{pH}$ corresponde à liberação de íons $\mathrm{OH}^{-}$no meio, considera-se essa variação proporcional à variação da concentração. As equações 2 e 3 a seguir são utilizadas para a regressão linear dos dados.

$\begin{array}{ccc}\mathrm{C}_{\mathrm{a}} & \mathrm{C}_{\mathrm{a} 0} & \mathrm{kt}\end{array}$

(ordem 0)

Equação 2

$\ln \frac{\mathrm{C}_{\mathrm{a} 0}}{\mathrm{C}_{\mathrm{a}}} \mathrm{kt} \quad($ ordem 1$)$

Equação 3

\section{RESULTADOS E DISCUSSÕES}

\subsection{Caracterização do óleo}

$\mathrm{Na}$ Tabela 1 a seguir podem-se verificar os valores médios para umidade, densidade, índice de acidez e peróxidos. É importante ressaltar que todas as análises foram realizadas em triplicatas.

Tabela 1: Parâmetros do óleo residual

\begin{tabular}{|c|c|}
\hline Parâmetros & Valor \\
\hline Umidade $(\%)$ & 1,3 \\
\hline Densidade $\left(\mathrm{Kg} / \mathrm{m}^{3}\right)$ & 0,9209 \\
\hline Índice de acidez $(\%)$ & 0,1090 \\
\hline Índice de Peróxidos $(\mathrm{meq} / \mathrm{kg})$ & 33 \\
\hline
\end{tabular}

O óleo residual apresentou um índice relativamente baixo de umidade e densidade compatível com o óleo de soja. O índice de acidez encontrado é bem abaixo do limite máximo 
para o descarte $(0,9 \%$ (ANVISA)). Sabe-se que quanto maior o número de frituras, maior a hidrólise do óleo e troca de umidade, resultando em maior geração de ácidos graxos livres. O valor encontrado indica que o óleo residual apresenta baixo índice de degradação. Entretanto, o índice de peróxidos é três vezes maior que o limite máximo recomendado para óleo novo (10 meq/kg (ANVISA)). Isto mostra que o óleo residual já estava em processo de degradação oxidativa, pois os peróxidos são produtos iniciais desta reação.

\subsection{Cinética da reação de saponificação}

A Tabela 2 mostra o resultado das cinco repetições que foram realizadas para a análise cinética, em relação à ordem de reação, equação de regressão e o coeficiente $\mathrm{R}^{2}$, nas amostras sem adição de extratos e correção do pH. O tempo de análise foi de $3600 \mathrm{~s}$.

Tabela 2: Resultados do levantamento cinético

\begin{tabular}{|c|c|c|c|}
\hline \multirow{2}{*}{ Repetição } & $\begin{array}{c}\text { Ordem da } \\
\text { Reação }\end{array}$ & Equação & $\mathrm{R}^{2}$ \\
\hline \multirow{2}{*}{$\mathrm{R} 1$} & Zero & $\mathrm{Y}=0,2 \times+12,04$ & 0,853 \\
\cline { 2 - 4 } & Primeira & $y 4.10^{5} \times 0,048$ & 0,869 \\
\hline \multirow{2}{*}{$\mathrm{R} 2$} & Zero & $y 0 \times 11,96$ & 0,823 \\
\cline { 2 - 4 } & Primeira & $y 4.10^{5} \times 0,08$ & 0,844 \\
\hline \multirow{2}{*}{$\mathrm{R} 3$} & Zero & $\mathrm{Y}=0,05 \mathrm{x}+12,2$ & 0,849 \\
\cline { 2 - 4 } & Primeira & $y .10^{5} \times 0,038$ & 0,858 \\
\hline \multirow{2}{*}{$\mathrm{R} 4$} & Zero & $\mathrm{Y}=0,08+12,77$ & 0,916 \\
\cline { 2 - 4 } & Primeira & $y 3.10^{5} \times 0,075$ & 0,936 \\
\hline \multirow{2}{*}{$\mathrm{R} 5$} & Zero & $\mathrm{Y}=0,04+12,79$ & 0,908 \\
\cline { 2 - 4 } & Primeira & $y 3.10^{5} \times 0,086$ & 0,978 \\
\hline
\end{tabular}

Em todos os casos verifica-se um bom ajuste de regressão, sendo que o valor de $\mathrm{R}^{2}$ foi maior para a reação de primeira ordem. Este é um indicativo de que os dados levantados neste trabalho se ajustam melhor ao modelo cinético de primeira ordem. Dados semelhantes foram obtidos por Souza (2013). Em todas as repetições, após a adição da solução de $\mathrm{NaOH}$, houve aumento do $\mathrm{pH}$ e da temperatura. $\mathrm{O}$ aumento de $\mathrm{pH}$ pode ser explicado devido à liberação de íons hidroxila $\left(\mathrm{OH}^{-}\right)$no meio e o aumento da temperatura, devido ao processo exotérmico reacional. O fim da reação é indicado pela estabilização do $\mathrm{pH}$ e redução da temperatura até a ambiente. Devido a dificuldades de quantificação do $\mathrm{pH}$, os resultados de levantamento cinético foram realizados apenas com a variação da temperatura.

\subsection{Bioensaios de atividade antimicrobiana}

Uma característica responsável pela ação antimicrobiana é a presença de compostos hidrofóbicos que permitem a partição de lipídeos da membrana celular bacteriana, desintegrando as estruturas e tornando-as mais permeáveis (Voss - Rech et. al, (2011)). Os halos de inibição medidos das placas com a bactéria $E$. coli não foram considerados por serem pequenos e com valor baixo. Os halos de inibição para $S$. aureus encontram-se na tabela 3.

Tabela 3: Halos de inibição para S.aureus dos três tipos de sabão 


\begin{tabular}{|c|c|c|}
\hline $\begin{array}{c}\text { Material acrescido } \\
\text { ao sabão }\end{array}$ & $\begin{array}{c}\text { Amostra de } \\
\text { sabão (mm) }\end{array}$ & $\begin{array}{c}\text { Disco de papel } \\
\text { (mm) }\end{array}$ \\
\hline \multirow{3}{*}{ C. Officinalis } & 10,00 & 14,00 \\
\cline { 2 - 3 } & 15,00 & 10,00 \\
\cline { 2 - 3 } & 15,00 & 10,00 \\
\hline Média & 13,33 & 13,33 \\
\hline \multirow{3}{*}{ S. adstringens } & 10,00 & 10,00 \\
\cline { 2 - 3 } & 15,00 & 10,00 \\
\cline { 2 - 3 } & 15,00 & 10,00 \\
\hline Média & 13,33 & 10,00 \\
\hline \multirow{3}{*}{ Própolis } & 13,00 & 15,00 \\
\cline { 2 - 3 } & 14,00 & 15,00 \\
\cline { 2 - 3 } & 15,00 & 15,00 \\
\hline Média & 14,00 & 15,00 \\
\hline
\end{tabular}

Os halos de inibição obtidos para S. aureus com as plantas C. officinalis, S. adstringens e com Própolis são expressivos e indicam aplicabilidade desse produto como antibacteriano. A adição de plantas medicinais em sabões mostra-se um processo inovador e promissor, uma vez que, existem diversas plantas medicinais que podem ainda ser testadas.

\section{CONCLUSÕES}

A produção de sabões em barra é uma alternativa viável e sustentável para a reutilização do óleo residual de fritura. Todas as plantas testadas apresentaram ação antimicrobiana, já que a adição de extratos das plantas medicinais aos sabões mostrou-se eficiente em seu poder antibacteriano em relação à Staphylococcus aureus, sendo a própolis a mais eficiente.

AGRADECIMENTO: Os autores agradecem o apoio financeiro provido pela FAPEMIG (PCE- 00455-17: Participação Coletiva em Eventos Técnico-Científicos).

\section{REFERÊNCIAS BIBLIOGRÁFICAS}

AGÊNCIA NACIONAL DE VIGILÂNCIA SANITÁRIA - ANVISA. Regulamento técnico para óleos e gorduras vegetais. Consulta pública ${ }^{\circ} 85,2004$.

ALBERICI, R. M.; PONTES, F. F. F. Reciclagem de óleo comestível usado através da fabricação de sabão. Eng. Ambiental Pesquisa e Tecnologia, v. 1, n.1, p. 73-76, 2004.

AMERICAN OIL CHEMISTS' SOCIETY - Official methods and recommended praticces of the American Oil Chemists`Society - A.O.C.S, 2009.

CORSINI, M. S.; JORGE, N. Estabilidade oxidativa de óleos vegetais utilizados em frituras de mandioca palito congelada. C. e T. de Alimentos, v. 26, n. 1, p. 27-32, 2006.

INSTITUTO ADOLFO LUTZ. Óleos e gorduras. In: Métodos físico-químicos para análise de alimentos. 1a ed digital. São Paulo: Instituto Adolfo Lutz, 2008. p. 593-629.

SOUZA, M. F. B. Aproveitamento de resíduos de óleos vegetais no desenvolvimento de sabões em barra enriquecidos com extratos de própolis e eucalipto. 2013. Dissertação, Universidade Federal de Goiás, Goiânia. 2013.

VOSS-RECH, D.; KLEIN, C. S.; TECHIO, V. H.; SCHEUERMANN, G. N.; RECH, G.; FIORENTIN, L. Antibacterial activity of vegetal extracts against serovars of Salmonella. Ciência Rural, v. 41, n. 2, p. 314-320, 2011. 